\title{
Optimal Efficiency Controller of AC Drive System
}

\author{
Rateb H. Issa \\ Mechatronics Engineering Department \\ Faculty of Engineering Technology \\ Al- Balqa Applied University
}

\begin{abstract}
This paper has presented a mathematical-based scheme for induction motor drive system leading to efficiency optimization. The proposed scheme uses information on torque of the squirrel cage motor to generate the appropriate voltage amplitude that maximizes the motor efficiency. A constantV/f efficiency controller model has been configured and built depending on a set of experimental data, based on the motor equivalent circuit, using Matlab computer program. The model was validated by simulation using a typical induction motor drive model implemented with Matlab/Simulink.

The aim of this paper is the drive system performance improvement by designing optimal efficiency controller; this will supply stator of the motor with proper voltage and frequency under different loading conditions using appropriate algorithm.
\end{abstract}

\section{General Terms}

Algorithms, Performance, Experimentation.

\section{Keywords}

Squirrel CageMotor, Efficiency, Drive System, Optimization, Modeling, Simulation.

\section{INTRODUCTION}

The importance of energy saving techniques implementation in industry can be pointed out from two points of view:

1 - It is well known that more than $60 \%$ of total generated electrical energy is consumed by electric motors in industry. Therefore, motor energy saving solutions by increasing its efficiency has received considerable attention during the last three decades due to the increase in energy cost [1] \& [2].

2- Three-phase asynchronous motors, especially the squirrel cage type are widely used in industrial electric drives and are responsible for most of energy consumed by electric motors in industry [3]\& [4].

Energy saving can be achieved by following means of electric drive system loss reduction:

A- Electric motor selection and design.

B- Improvement of power supply parameters.

C- Utilizing a suitable optimal control technique.

Motor operation under rated conditions is highly efficient [5], however, in many applications, when induction motor works at variable speed it has more losses and less efficiency, so it operates far from the rated point[6].

Under these circumstances, it is not possible to improve the motor efficiency by motor design or by supply waveform shaping technique. Therefore, a suitable control algorithm that minimizes the motor losses will rather take place [7]-[9].
The need of efficient drive system could be achieved by special controllers that not only modify the losses and efficiency, but also searching for the optimal efficiency to reduce the power consumption from the source [10]-[13]

In this paper will be designed an optimal efficiency Controller, which will minimize the motor losses under different loading conditions, by varying stator voltage and frequency as a function of motor load torque, depending on industrial machinery type.

\section{AC Drive System Components}

The block diagram of voltage source inverter-three-phase squirrel cage induction motor drive system is presented in Figure 1. It consists of three-phase squirrel cage induction motor, IGBT-voltage source inverter-based AC-to-AC converter, and optimal controller [10]. In order to analyze the system performance, all of these components should be modeled [14] \& [15].

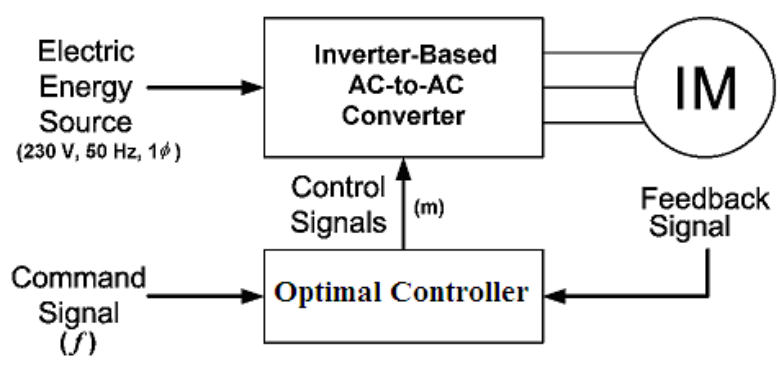

Fig 1: Block diagram of an inverter-three-phase squirrel cage induction motor drive system

\subsection{Squirrel Cage Induction Motor}

AC drive systems are used worldwide in many residential, commercial, industrial, and utility applications. Electric motors transform electrical energy into mechanical energy. An AC motor may be part of pump or fan, or connected to some other form of mechanical equipment such as a winder, conveyor, or mixer.

\subsubsection{Per-Phase Equivalent Circuit of Induction Motor}

Theper-phaseequivalent circuit of induction motor is shown on figure 2 [16].

Where:

$\mathrm{R}_{1}$ : Stator resistance.

$\mathrm{R}_{2}^{\backslash}$ : Rotor resistance referred to stator circuit. 


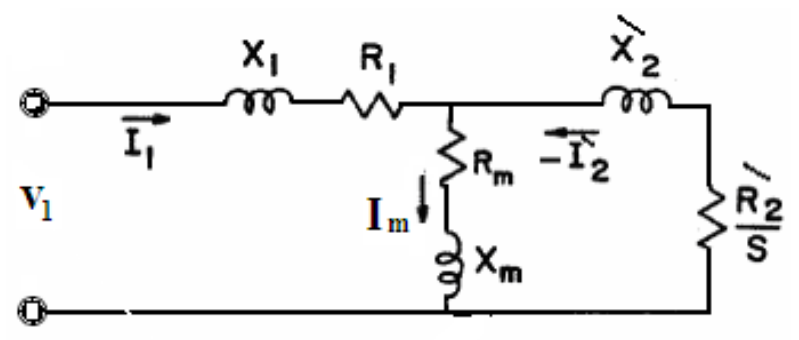

Fig 2: Per-phase equivalent circuit of induction motor

$\mathrm{R}_{\mathrm{m}}$ : Magnetizing resistance.

$\mathrm{X}_{1:}$ Stator reactance.

$\mathrm{X}_{2:}^{\prime}$ Rotor reactance referred to stator circuit.

$\mathrm{X}_{\mathrm{m}}$ : Magnetizing reactance.

$\mathrm{I}_{1}$ : Stator current.

$I_{2}^{\prime}$ : Rotor current referred to stator circuit.

$\mathrm{I}_{\mathrm{m}}$ : Magnetizing current.

$\mathrm{V}_{1}$ : Applied phase voltage.

$\mathrm{S}:$ Slip of the motor

Slip is defined by:

$$
S(\underline{1}) \frac{\omega_{0}-\omega}{\omega_{0}}
$$

Where:

$\omega_{\mathrm{o}}:$ Synchronous speed $[\mathrm{red} / \mathrm{sec}]$.

$\omega:$ Rotor speed [red/sec].

$$
\omega_{\mathrm{o}}=\frac{4 \pi \mathrm{f}}{\mathrm{P}} \text { Where: }
$$

f : Three phase source's frequency $[\mathrm{Hz}]$.

$\mathrm{P}:$ Number of poles.

\subsubsection{Power Flow Diagram of Induction Motor}

The Power flow diagram of induction motor is shown on figure 3[17].

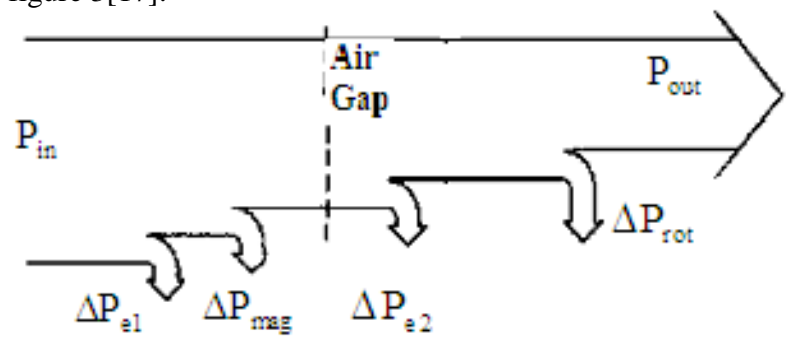

Fig 3: Power flow diagram of induction motor

The power flow diagram components are:

Input power is given by:

$P_{\text {in }}=3 V_{1} I_{1} \cos \varphi_{1}$ (3)

Stator copper losses are given by:

$$
\Delta \mathrm{P}_{\mathrm{el}}=3 \mathrm{I}_{1}^{2} \mathrm{R}_{1}(4)
$$

Magnetic losses are given by:

$$
\Delta \mathrm{P}_{\text {mag }}=3 \mathrm{I}_{\mathrm{m}}^{2} \mathrm{R}_{\mathrm{m}}(5)
$$

Rotor copper losses are given by:

$$
\Delta \mathrm{P}_{\mathrm{e} 2}=3 \mathrm{I}_{2}^{\prime 2} \mathrm{R}_{2}=\mathrm{SP}_{\mathrm{em}}(6)
$$

$$
\mathrm{P}_{\mathrm{em}}=\mathrm{T} \omega_{\mathrm{o}}
$$

Mechanical and additional losses are given by:

$$
\Delta \mathrm{P}_{\text {rot }}=0.015 \mathrm{P}_{\text {out }} \text { (8) }
$$

Output power is given by:

$$
\mathrm{P}_{\text {out }}=\mathrm{T} \omega
$$

The torque- speed characteristic of the induction motor is described by:

$$
\mathrm{T}=\frac{3 \mathrm{~V}_{1}^{2} \mathbf{R}_{2}^{\prime}}{\mathrm{S} \omega_{\mathrm{o}}\left[\left(\mathrm{R}_{1}+\frac{\mathrm{R}_{2}^{\prime}}{\mathrm{S}}\right)^{2}+\mathrm{X}_{\mathrm{SC}}^{2}\right]}
$$

\subsubsection{Parameters of Induction Motor}

The rated values and parameters for 3-phase induction motor squirrel cage type are given in table 1.

Table1. Parameters of three- phase squirrel cage induction motor

\begin{tabular}{|l|l|}
\hline Number of Poles & 4 \\
\hline Rated Output Power & $4[\mathrm{~kW}]$ \\
\hline Rated Voltage, $\mathrm{V}_{\mathrm{L}-\mathrm{L}}$ & $400[\mathrm{~V}]$ \\
\hline Rated Frequency, $\mathrm{f}$ & $50[\mathrm{~Hz}]$ \\
\hline Rated Slip, $\mathrm{S}_{\text {on }}$ & 0.0466 \\
\hline Stator Resistance, $\mathrm{R}_{1}$ & $1.405[\Omega]$ \\
\hline Rotor Resistance, $\mathrm{R}_{2}$ & $1.395[\Omega]$ \\
\hline Stator Inductance, $\mathrm{L}_{1}$ & $0.005839[\mathrm{H}]$ \\
\hline Rotor Inductance, $\mathrm{L}_{2}^{\prime}$ & $0.005839[\mathrm{H}]$ \\
\hline Magnetizing Inductance, $\mathrm{L}_{\mathrm{m}}$ & $0.1722[\mathrm{H}]$ \\
\hline Total moment of Inertia, $\mathrm{J}_{\epsilon}$ & $0.01\left[\mathrm{~kg} \cdot \mathrm{m}^{2}\right]$ \\
\hline
\end{tabular}

\subsection{Optimal Controller}

The optimal control system is a closed loop system, used to drive or control processes and keep the variables in these processes at optimal values in spite of the influences that affect it. The optimal control system is also a programmed controller and has the ability to adaptive searching for the optimal values of the variables when the changes affect the process.

There are several optimal control techniques, used to optimize AC drive system, some of these techniques are [18]\& [19]:

$$
\text { 1- Minimum stator current. }
$$

2- Minimum total losses.

3- Maximum Efficiency.

4- Maximum power factor.

Focus in this paper will be on maximum efficiencyoptimization technique.

Electromagnetic (air gap) power is given by: 


\section{Squirrel Cage Induction Motor Efficiency Optimization}

In general, there are three different approaches to improve the induction motor efficiency especially under light load conditions [20] namely loss model controller (LMC), search controller (SC), and lookup table scheme. This paper considers the loss model controller.

The electric motor efficiency represents the machine behavior during the electric power conversion into mechanical power, and defined as [21]:

$$
\eta=\frac{P_{\text {out }}}{P_{\text {out }}+\Delta P_{\Sigma}}
$$

The total losses $\left(\Delta \mathrm{P}_{\Sigma}\right)$ comprises of copper losses in stator and rotor, iron losses due to eddy current and hysteresis, stray losses arise on the copper and iron of the motor, friction losses and finally converter loses due to the resistance offered by the solid state switches. Power output is the product of shaft load and its speed.

\subsection{Modeling of AC Drive System Using Matlab Simulink Toolbox}

\subsubsection{Modeling of Optimal Controller}

The inverter-based AC-to-AC Converter is considered an ideal system, where the DC voltage at the input of the inverter has no AC component, and the output voltage of the filter at the output of the inverter has no harmonics (just the fundamental wave is considered).

The ratio of the amplitude of the sinusoidal waveform to the amplitude of the triangular waveform is called the modulation index (Ma). The modulation index is in the range of (0 to 1$)$. The relationship between the modulation index and the RMS value of the phase voltage waveform is [14]:

$\mathrm{V}=\mathrm{M}_{\mathrm{a}} \mathrm{V}_{\text {in }}(12)$

Where:

$\mathrm{V}$ : The RMS value of phase output voltage of the converter.

$\mathrm{V}_{\text {in }}$ : The RMS value of phase base voltage of the converter.

Notice that $\mathrm{V}_{\text {in }}$ is equal to the nominal voltage $\mathrm{V}_{\mathrm{N}}$, so equation (12) can be written as:

$\mathrm{V}=\mathrm{M}_{\mathrm{a}} \mathrm{V}_{\mathrm{N}}(13)$

So changing the modulation index and the sinusoidal waveform frequency will change the RMS value of the output voltage and frequency, respectively.

Equation (12) gives the static voltage model.

The Steady-State frequency model is:

$\mathrm{f}=\mathrm{f}_{\text {in }}$

Where:

$\mathrm{f}$ : Frequency of the output voltage of the converter.

$f_{\text {in }}$ : Frequency of the sinusoidal waveform.

Figure 4 shows the model of constant V/f controller.

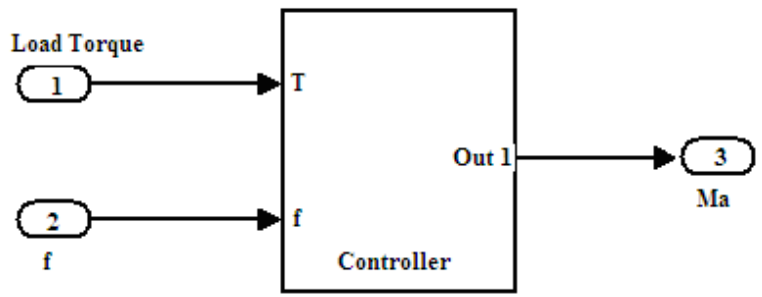

Fig 4: The model of V/f controller

\subsubsection{Modeling of Induction Motor Total Losses}

The induction motor total losses $\left(\Delta \mathrm{P}_{\Sigma}\right)$ can be calculated by:

$$
\Delta \mathrm{P}_{\Sigma}=\Delta \mathrm{P}_{\mathrm{e} 1}+\Delta \mathrm{P}_{\text {mag }}+\Delta \mathrm{P}_{\mathrm{e} 2}+\Delta \mathrm{P}_{\text {rot }}
$$

Substituting equations (4), (5), (6), (7) and (8)in Eq. (15):

$$
\begin{aligned}
& \Delta \mathrm{P}_{\Sigma}=3 \mathrm{I}_{1}^{2} \mathrm{R}_{1}+\Delta \mathrm{P}_{\operatorname{magN}}\left(\frac{\mathrm{V}_{1}}{\mathrm{~V}_{1 \mathrm{~N}}}\right)^{2}\left(\frac{\mathrm{f}_{1}}{\mathrm{f}_{1 \mathrm{~N}}}\right)^{0.5}+ \\
& +\mathrm{T} \omega_{\mathrm{o}} \mathrm{S}+0.015 \mathrm{P}_{\text {out }}
\end{aligned}
$$

Where:

$$
\Delta \mathrm{P}_{\text {magN }} \text { - Magnetizing nominal losses. }
$$

The induction motor total losses model is shown on figure 5 .

\subsection{Optimal Efficiency Controller at Different Frequencies Design}

Curve Fitting method is used to build the optimal efficiency controller's equation that computes the modulation index. The modulation index controls the value of applied stator voltage to satisfy maximum efficiency at any value of load torque.

By using Curve Fitting Toolbox, controller's equation was derived from the following data set, given in table 2, which represent values of variant loads with the optimal voltage's values; these values satisfythe maximum efficiency.

Table 2 Optimal voltage's values of variant load at $(\mathrm{f}=50 \mathrm{~Hz})$

\begin{tabular}{|l|l|}
\hline Load Torque, T & Optimal Voltage, $\mathrm{V}_{\mathrm{opt}}$ \\
\hline 20 & 230.94 \\
\hline 18 & 225 \\
\hline 16 & 205 \\
\hline 14 & 190 \\
\hline 12 & 180 \\
\hline 10 & 170 \\
\hline 8 & 155 \\
\hline 6 & 125 \\
\hline 4 & 100 \\
\hline 2 & 75 \\
\hline
\end{tabular}




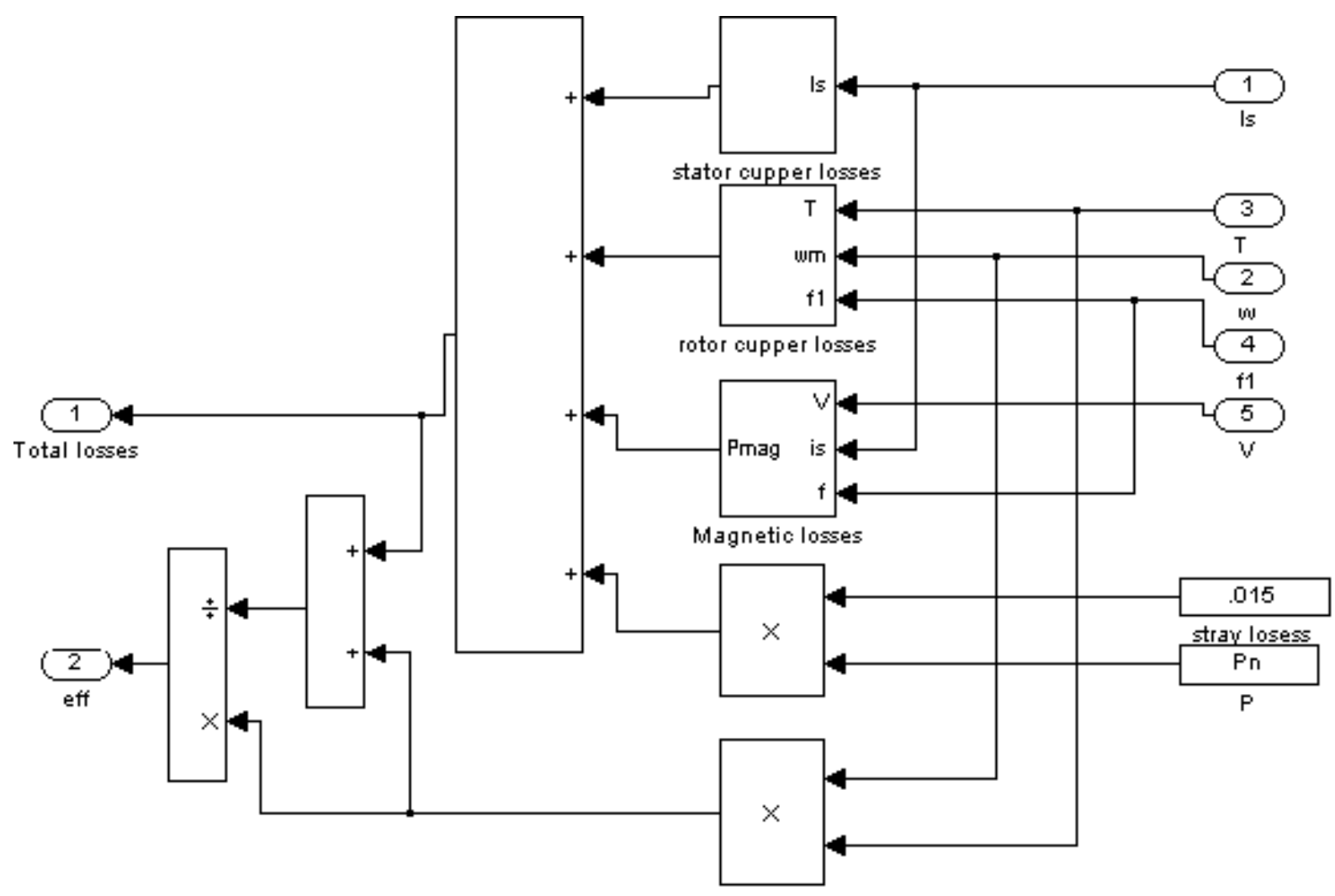

Fig 5: Induction motor total losses model

Optimal efficiency controller's equation at $\mathrm{f}=50 \mathrm{~Hz}$ derived using the following steps:

1- The above data set must be loaded in the

MATLAB workspace.

2- Import data into the Curve Fitting Tool.

3.After fitting the previous data, we got the fitting curve.

4. From the fitting editor we got equation coefficients.

5. The resultant controller's equation at nominal frequency is:

$V_{\text {opt }}=-a_{1} T^{7}+a_{2} T^{6}-a_{3} T^{5}+a_{4} T^{4}-$

$$
-a_{5} T^{3}+a_{6} T^{2}+a_{7} T+a_{8}
$$

Where:

$\mathrm{a}_{1}, \mathrm{a}_{2}, \ldots, \mathrm{a}_{8}$ are constants

$\mathrm{a}_{1}=3.698 \times \mathrm{e}^{-7}, \mathrm{a}_{2}=4.292 \times \mathrm{e}^{-5}$

$\mathrm{a}_{3}=0.001913, \mathrm{a}_{4}=0.04077, \mathrm{a}_{5}=0.4122$,

$\mathrm{a}_{6}=1.229, \mathrm{a}_{7}=16.12, \mathrm{a}_{8}=38.95$

Following the above mentioned steps different controllers could be built; each of them can control the drive system at certain frequency. Automatic switch can select proper controller, which apply the optimal voltage at desired frequency.
Automatic switch has five input ports, one port for each controller. The automatic switch uses control signal (CS) to determine proper input port (suitable controller). The control signal computed by the following equation:

$$
\mathrm{CS}=-0.1 \mathrm{f}+6(18)
$$

Figure 6 shows the optimal efficiency controller model at different frequencies using automaticswitch.

\section{Optimized AC Drive System Model}

The optimized drive system model consists of the following blocks:

1- AC squirrel cage induction motor model.

2- Inverter model.

3- Optimal efficiency controller model at different frequencies using automatic switch.

4- Induction motor total losses model

The model of optimized drive system is shown on figure 7. 


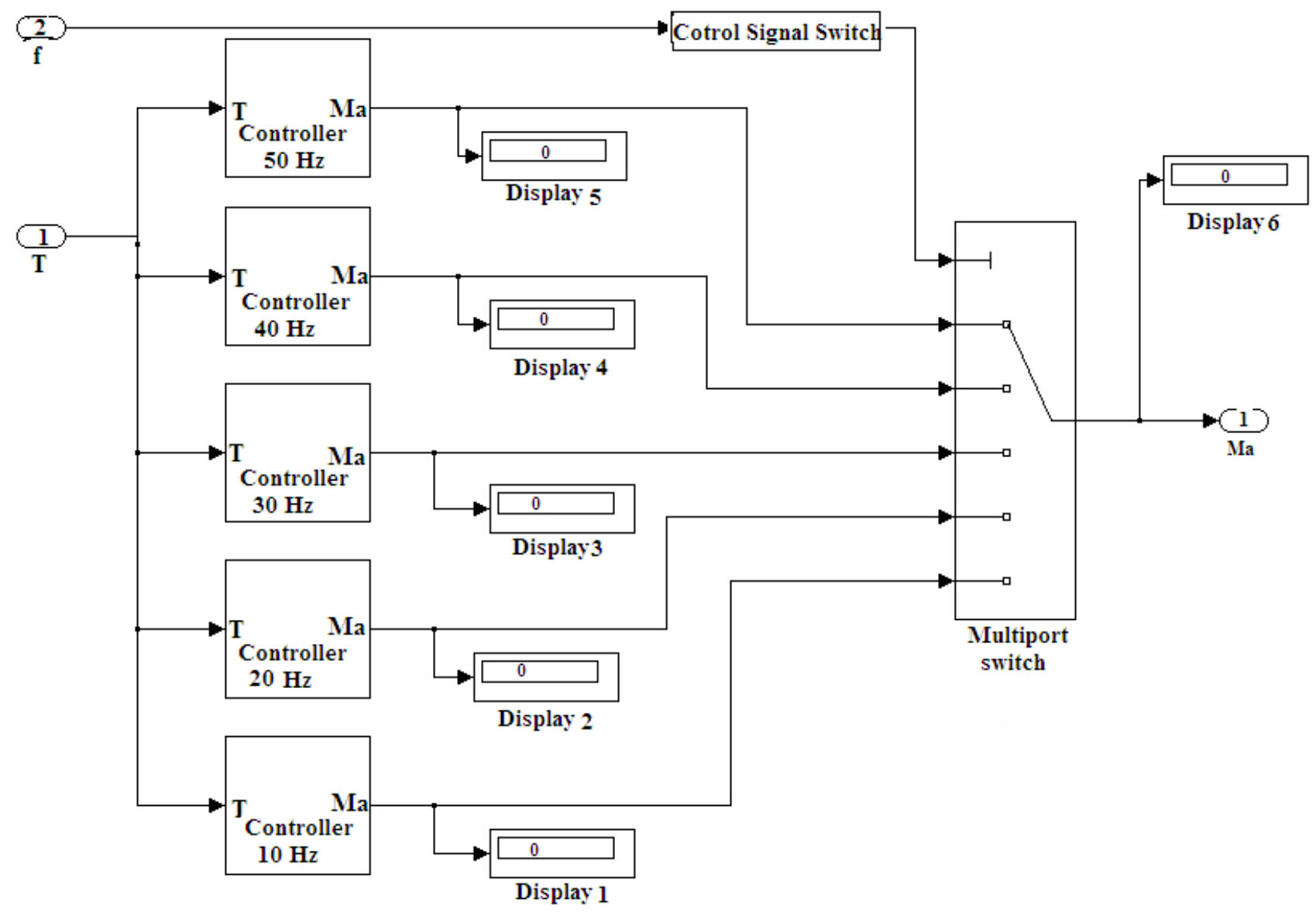

Fig 6: Optimal efficiency controller model at different frequencies using automatic switch

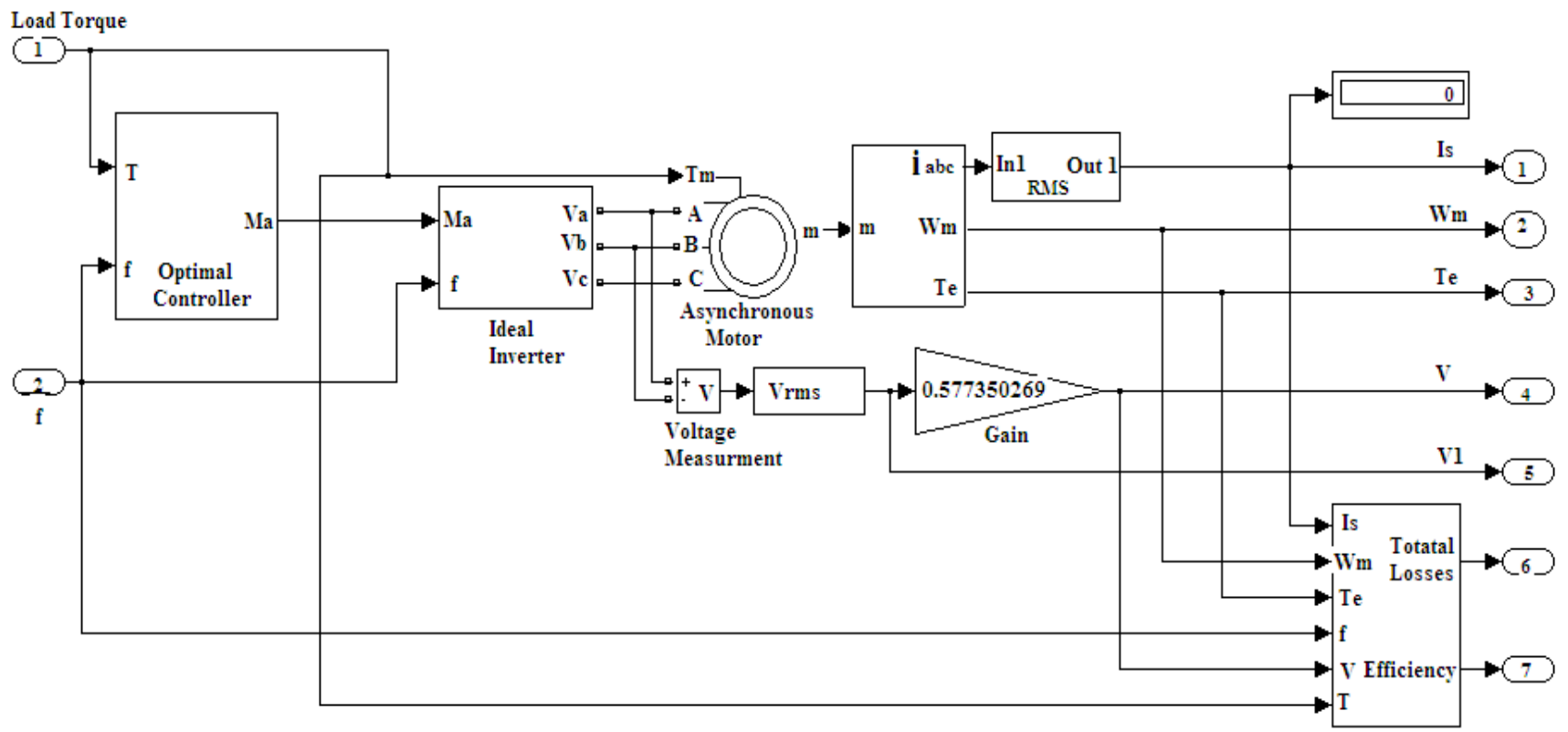

Fig 7: Optimized ac drive system model 


\section{Simulation Results}

Using the model of AC drive system with constant V/f optimal efficiency controller, we have the following simulation results:

1- Figures (8, 9 and 10) represent efficiency relationship versus load torque for both open loop and optimized AC drive systems at different frequencies ( $\mathrm{f}=50 \mathrm{~Hz}, 30 \mathrm{~Hz}$ and $10 \mathrm{~Hz}$ ).

2- Figures (11, 12 and 13) represent real time steady-state efficiency relationship under different load torques for both open loop and optimized ac drive systems at different frequencies ( $\mathrm{f}=50 \mathrm{~Hz}, 30 \mathrm{~Hz}$ and $10 \mathrm{~Hz}$ ).

3- Figure 14 represents real time steady-state efficiency relationship under constant load torque at different frequencies.

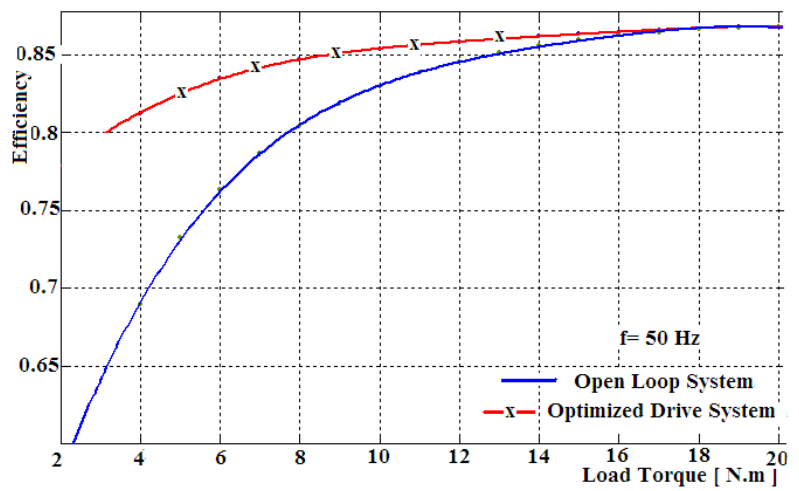

Fig 8: AC drive system efficiency at $\mathrm{f}=50 \mathrm{~Hz}$

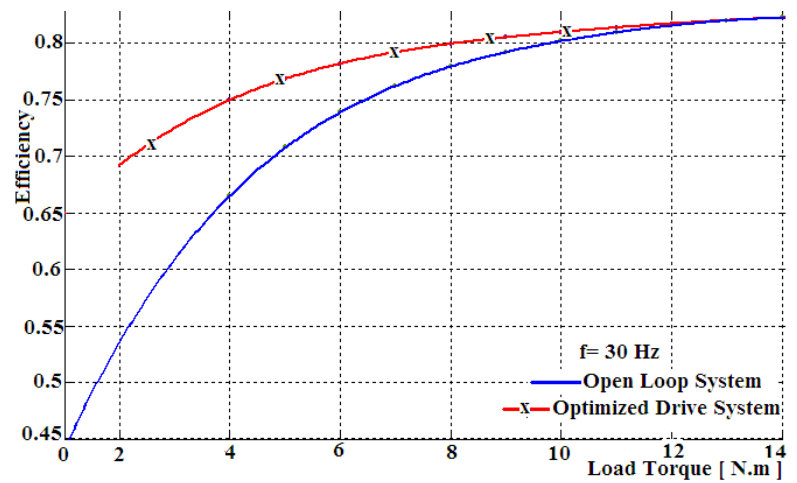

Fig 9: AC drive system efficiency at $\mathrm{f}=30 \mathrm{~Hz}$

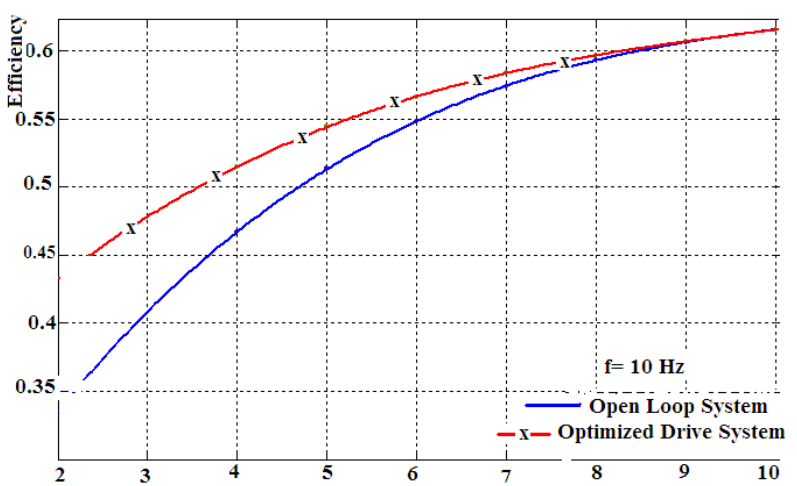

Fig 10: AC drive system efficiency at $f=10 \mathrm{~Hz}$

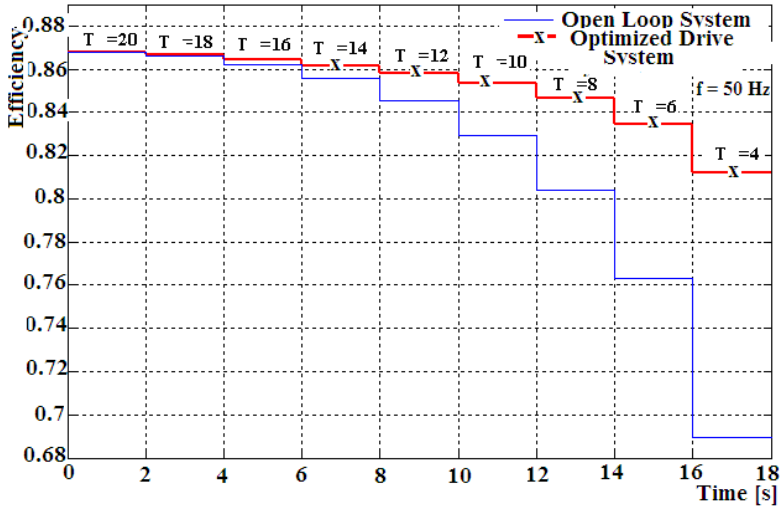

Fig 11: Real time AC drive system efficiency at $\mathrm{f}=\mathbf{5 0 H z}$

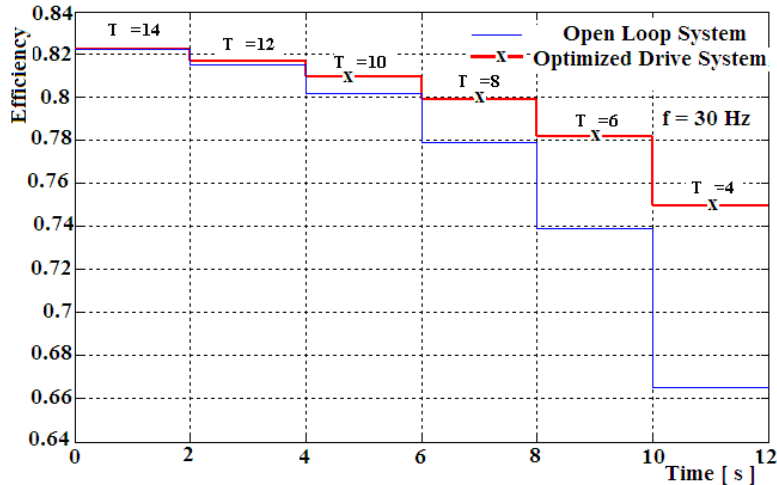

Fig 12: Real time AC drive system efficiency at $f=30 \mathrm{~Hz}$

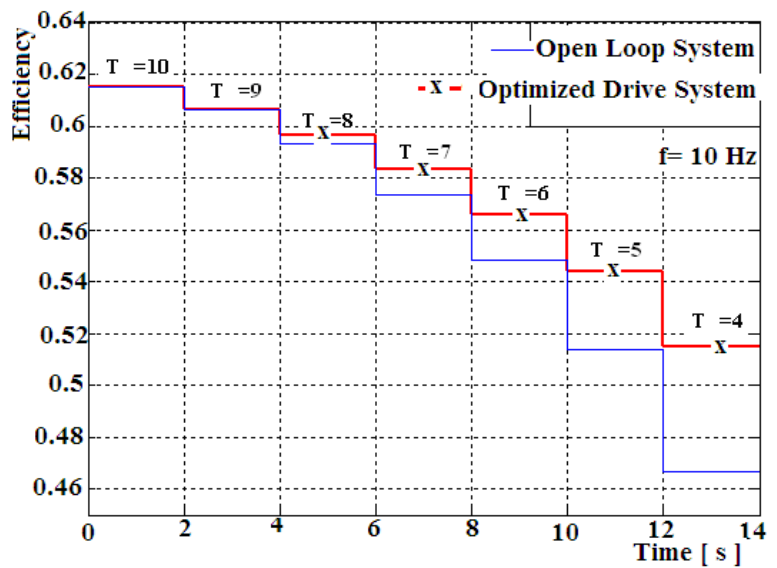

Fig 13: Real time AC drive system efficiency at $\mathrm{f}=10 \mathrm{~Hz}$

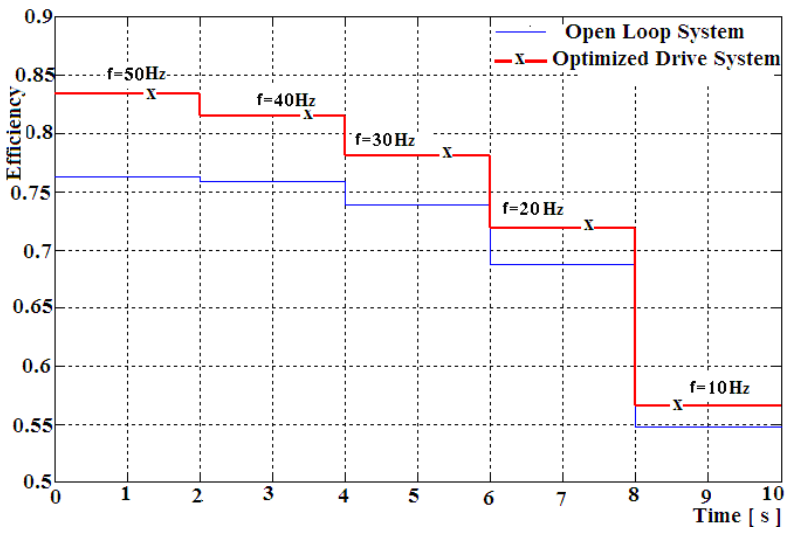

Fig 14: Real time AC drive system efficiency at different frequencies and constant load 


\section{Discussions and Conclusions}

The proposed technique can be implemented on AC drive systems equipped with load torque sensor and for which the steady state speed- torque characteristics are known.

The advantages that can be gained with the proposed efficiency optimization algorithm are tremendous, and energy savings can be achieved with a high percentage.

Studying and analyzing the above shown figures of simulation results, we can conclude that:

1- Implementation of constant V/f optimal efficiency has improved the efficiency of optimized drive system, in comparison with the efficiency of open loop drive system working at different frequencies and load torques.

2- Tangible improvement of drive system efficiency is noticed at light load torques.

3- Efficiency improvement range becomes less, when decreasing applied frequency.

\section{REFERENCES}

[1] Millie Pant, Radha Thangarajn and Singh V.P. Efficiency Optimization of Electric Motors: a Comparative Study of Stochastic Algorithms, World Journal of Modeling and Simulation, 2008, Vol. 4, No. 2, pp. 140-148.

[2] Vaez-Zadhe, S. and Hendi, F. A.Continuous Efficiency Controller for Induction Motor Drives, Energy Conversion and Management, 2005, 46, pp.701-713.

[3] Garcia, G. and Luis, J. An Efficient Controller for an Adjustable Speed Induction Motor Drive. IEEE Trans. Ind. Elec., 1994, 31(5), pp. 533-539.

[4] Thanga Raj,C., Srivastava, S.P. and Pramod agarwal.Differential Evolution Based Optimal Control ofInduction Motor Serving to Textile Industry, IAENGInternational Journal of Computer Science, 2008,35:2,pp. 1-8.

[5] Palit, B.B. Energy Saving Operation in Induction Motorsby Voltage Reduction at No- and Low Partial Load, inProc. IEEE Ind. Appl. Annual Meeting, 1989, pp.147-151.

[6] Muravlev, O. and Vekhter, E. Energetic Parameters ofInduction Motors as the Basis of Energy Saving in aVariable Speed Drive, Electric Power Quality andUtilization, 2005, Vol.IX, N.2.

[7] Lim,S. Nam, k. Loss-Minimizing Control Scheme forInduction Motors, IEEE Proc. -Electr. Power Appl.,July 2004, Vol.151, No. 4,

[8] Feng-Chien Lin, Shing-Ming Yang, On-Line Tuning of an Efficiency- Optimized Vector Controlled Induction Motors Drives, Tamkang Journal of Science and Engineering, 2003, Vol. 6, No. 2.
[9] Rateb H. Issa, Energy Saving in Electric Elevators with Random Loading Diagram, Journal of Engineering Studies \& Research, Baghdad, 1997,Vol.4, No.2.

[10] Rateb Issa. Three-Phase Induction Motor Stator Current Optimization, IJCA Special Issue on' Evolutionary Computation for Optimization Techniques" ECOT, 2010, pp.41-50.

[11] Alfredo M.G, Thomas A.L and Donald W.N, A New Induction Motor V/f Control Method Capable on Industry Applications, vol. 34, No. 4, July- August, 1998, pp. 813-820.

[12] Rasmus K. Ursem, Models for evolutionary Algorithms and Their Applications in System Identification and Control Optimization, BRICS, 2003.

[13] Minh Ta-Cao, Yoichi Hori, Convergence Improvement of Efficiency Optimization Control of Induction Motor Drive, Industrial Applications Conference,2000, Conference record of IEEE, Vol. 3, pp. 1662-1669.

[14] Hussein Sarhan and Rateb Issa, Modeling, Simulation and Test of Inverter Induction Motor Drive System with Improved Performance, Journal of Engineering Sciences,Asuit Univerisity,2005,Vol.33,No.5

[15] Krishna, R. Electric Motors Drives Modeling, Analysis, and Control, Prentice Hall, 2001.

[16] Dubey , G. K. Fundamentals of Electric Drives , Narose Publishing House, second edition,2002

[17] Rateb Issa ,Zeid Hijazin,Electric Motors Drive, AlMujtama’ Al-Arabi Publisher,Amman,Jordan, 2007.

[18] Hussein Sarhan, Rateb Issa and Mohammad Alia, Optimal Power Factor Control of Three-Phase Induction Motor Drives Using PIC-Microcontroller, International Review of Automatic Control,2012, Vol.5,N.3, pp.349353.

[19] Rateb Issa, Hussein Sarhan and Ijreid Al-Khawaldeh, Modeling and Simulation of Flux- Optimized Induction Motor Drive, Research Journal of Applied sciences, Engineering and Technology,2010, Vol.2,N.6,pp. 603613.

[20] Hamid, R and Amin, A.M.A. New Technique for Maximum Efficiency of Induction Motors Based on PSO, IEEE conference proceedings, 2006, pp.21762181.

[21] Kioskeridis,I. and Margaris,N. Loss Minimization in Scalar Controlled Induction Motor Drives with Search Controller.IEEE Trans. Power Elec., 1996, 11(2), pp.213 -220 . 